\title{
Morphology and constitution of the compound layer formed on nitrided Fe-4wt.\%V alloy
}

\author{
Santosh S. Hosmani · Ralf E. Schacherl • \\ Eric J. Mittemeijer
}

Received: 18 January 2008/Accepted: 27 October 2008/Published online: 23 November 2008

(c) The Author(s) 2008. This article is published with open access at Springerlink.com

\begin{abstract}
The microstructure of the compound ("white") layer formed on the surface of $\mathrm{Fe}-4 \mathrm{wt} . \% \mathrm{~V}$ alloy, by nitriding in a gas mixture of ammonia and hydrogen at $580{ }^{\circ} \mathrm{C}$, has been investigated by employing light and scanning electron microscopy, X-ray diffraction and electron probe microanalysis. The compound layer is dominantly composed of $\gamma^{\prime}-\mathrm{Fe}_{4} \mathrm{~N}$ nitride. Quantitative analysis of the composition data demonstrated that $\mathrm{V}$ is present in the compound layer as $\mathrm{VN}$ precipitates, i.e. $\mathrm{V}$ is not taken up significantly in $(\mathrm{Fe}, \mathrm{V})$ nitrides. A mechanism for compound-layer formation has been proposed.
\end{abstract}

\section{Introduction}

Nitriding of $\mathrm{Fe}-\mathrm{V}$ alloys was the subject of several, also recent investigations [1-10]. In these investigations, attention was solely paid to the ferritic zone, close to the surface, where vanadium-nitride precipitates develop in the ferritic matrix (internal nitriding), i.e. the formation of the diffusion zone. In the case of nitrided $\mathrm{Fe}-\mathrm{V}$ alloys, no

S. S. Hosmani · E. J. Mittemeijer

Max Planck Institute for Metals Research, Heisenbergstr. 3,

70569 Stuttgart, Germany

e-mail: s.hosmani@mf.mpg.de

E. J. Mittemeijer

e-mail: e.j.mittemeijer@mf.mpg.de

R. E. Schacherl $(\bowtie) \cdot$ E. J. Mittemeijer

Institute for Physical Metallurgy, University of Stuttgart,

Heisenbergstr. 3, 70569 Stuttgart, Germany

e-mail: r.schacherl@mf.mpg.de research has focused on the formation of the surface layer, usually indicated as compound layer and also as "white layer", which is (dominantly) composed of iron nitrides (external nitriding). Such a compound layer can bring about distinct improvement of the tribological and anti-corrosion properties [11-13]. The present study involves an analysis of the microstructure of the compound layer formed on nitrided $\mathrm{Fe}-4 \mathrm{wt} . \% \mathrm{~V}$ alloy. In particular, it was investigated whether or not the alloying element $\mathrm{V}$ is incorporated (dissolved) in the iron nitride formed.

\section{Experimental}

$\mathrm{Fe}-4 \mathrm{wt} . \% \mathrm{~V}$ alloy was prepared from pure $\mathrm{Fe}(99.98 \mathrm{wt} . \%)$ and pure $\mathrm{V}$ (99.80 wt.\%) by melting under argon atmosphere (99.999 vol.\%) in an $\mathrm{Al}_{2} \mathrm{O}_{3}$ crucible using an inductive furnace. The composition of the ingot, as determined by chemical analysis (inductive-coupled plasmaoptic emission spectroscopy), is shown in Table 1.

The cast of the Fe-4wt.\% V alloy was cold rolled to about 1.1-mm-thick sheets. These sheets were cut into pieces with lateral dimensions $1.5 \times 1.5 \mathrm{~cm}^{2}$. The sheet pieces were annealed at $700{ }^{\circ} \mathrm{C}$ for $2 \mathrm{~h}$ to get a recrystallized grain structure. Next, before nitriding, the specimens were ground, polished (last step: $1 \mu \mathrm{m}$ diamond paste) and cleaned in an ultrasonic bath filled with ethanol.

The specimens were (gaseously) nitrided at $580{ }^{\circ} \mathrm{C}$ for 12 and $48 \mathrm{~h}$ at the nitriding potential of $0.54 \mathrm{~atm}^{-1 / 2}$ ( $345 \mathrm{~mL} / \mathrm{min}$ hydrogen and $155 \mathrm{~mL} / \mathrm{min}$ ammonia; for definition of nitriding potential, see Ref. [14]). Under these nitriding conditions iron nitrides can be formed at the surface [15]. 
Table 1 Amounts of vanadium and light element impurities for the $\mathrm{Fe}-4 \mathrm{wt} . \% \mathrm{~V}$ alloy used in this work

\begin{tabular}{|c|c|c|c|c|c|c|c|}
\hline & V (wt.\%) & $\mathrm{V}$ (at.\%) & O (wt.\%) & $\mathrm{N}($ wt.\%) & $\mathrm{C}$ (wt.\%) & S (wt.\%) & $\mathrm{Fe}$ \\
\hline $\mathrm{Fe}-4 \mathrm{wt} . \% \mathrm{~V}$ & $4.05 \pm 0.07$ & $4.42 \pm 0.07$ & $0.0155 \pm 0.0010$ & $<0.0006$ & $0.0006 \pm 0.0003$ & $0.0005 \pm 0.0002$ & Bal. \\
\hline
\end{tabular}

Two pieces were cut from each nitrided specimen. One piece of each specimen was prepared to a cross section by embedding (PolyFast, Buehler $\mathrm{GmbH}$ ) and polishing (last step: $0.25 \mu \mathrm{m}$ diamond paste). Such prepared cross sections were subjected to electron probe microanalysis (EPMA) of the elements $\mathrm{N}, \mathrm{V}$ and Fe. The procedure for EPMA has been described in detail in Ref. [16]. After EPMA analysis the cross sections were etched using $2.5 \%$ nital (2.5 vol.\% $\mathrm{HNO}_{3}$ in ethanol) for about $5 \mathrm{~s}$ and investigated by light optical microscopy.

Non-embedded pieces of the nitrided specimens were used for X-ray diffraction phase analysis. A Philips X'Pert diffractometer was used applying $\mathrm{Cu} \mathrm{K}_{\alpha}$ and $\mathrm{Co} \mathrm{K}_{\alpha}$ radiations and employing the Bragg-Brentano geometry with a graphite monochromator in the diffracted beam. The diffraction angle $(2 \theta)$ range scanned was $10-150^{\circ}$, with a step size of $0.05^{\circ}$ and a counting time of $8 \mathrm{~s}$ per step. The X-ray diffractograms were recorded from specimen surfaces as obtained after nitriding. To identify the phases from the positions of the diffraction peaks, the data from the JCPDS database [17] were used.

\section{Results and discussion}

Phase identification and morphology of the nitrided zone

$\mathrm{X}$-ray diffractograms recorded from the surface of $\mathrm{Fe}-4 \mathrm{wt} . \% \mathrm{~V}$ specimen nitrided at $580{ }^{\circ} \mathrm{C}$ for $48 \mathrm{~h}$ at nitriding potential of $0.54 \mathrm{~atm}^{-1 / 2}$ by employing Co $\mathrm{K}_{\alpha}$ $(\lambda=0.178897 \mathrm{~nm})$ and $\mathrm{Cu} \mathrm{K}_{\alpha}(\lambda=0.154056 \mathrm{~nm})$ radiations are shown in Fig. 1. The X-ray diffractograms show reflections of $\gamma^{\prime}-\mathrm{Fe}_{4} \mathrm{~N},{ }^{1} \alpha-\mathrm{Fe}$ and $\mathrm{VN}$. The diffractogram recorded with $\mathrm{Co}_{\alpha}$ shows a relatively higher intensity for the $\alpha$-Fe reflexes than the diffractogram recorded with $\mathrm{Cu}$ $\mathrm{K}_{\alpha}$, which is due to the higher penetration depth of the Co $\mathrm{K}_{\alpha}$ radiation $(\alpha-\mathrm{Fe}$ is present underneath the compound layer). Similar results were obtained for the specimen nitrided for $12 \mathrm{~h}$.

Optical micrographs of the cross sections (at three different locations) of the $\mathrm{Fe}-4 \mathrm{wt}$. $\% \mathrm{~V}$ specimens nitrided for

\footnotetext{
${ }^{1}$ The $\gamma^{\prime}$ phase is normally slightly understoichiometric, i.e. $\gamma^{\prime}-\mathrm{Fe}_{4} \mathrm{~N}_{1-x}$, with $x>0$ and very small [15]. It will be denoted here as $\mathrm{Fe}_{4} \mathrm{~N}$, unless indicated otherwise specifically.
}
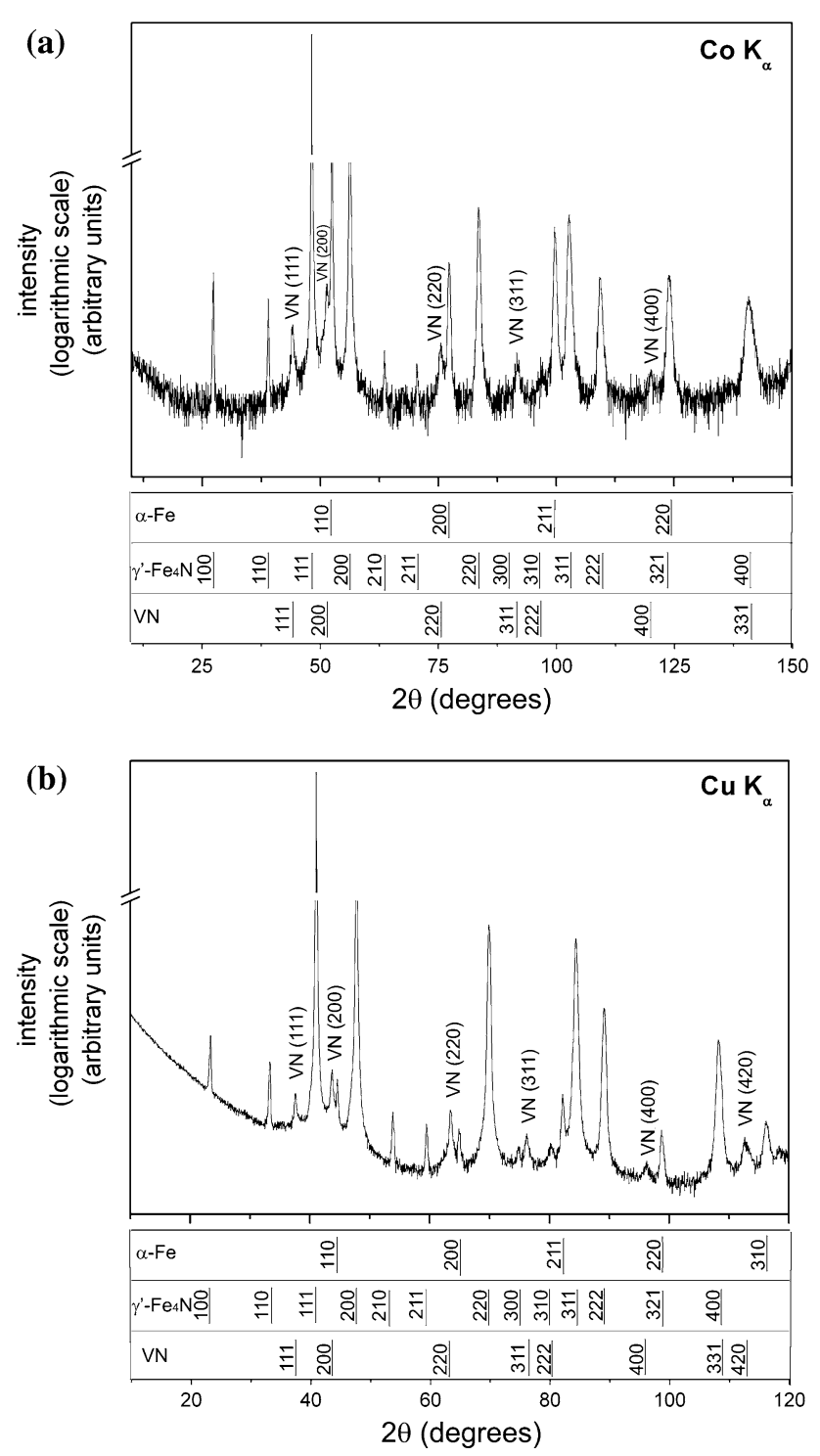

Fig. 1 X-ray diffractograms recorded from the surface of a $\mathrm{Fe}-$ $4 \mathrm{wt} . \% \mathrm{~V}$ specimen, nitrided at $580{ }^{\circ} \mathrm{C}$ for $48 \mathrm{~h}$ at a nitriding potential of $0.54 \mathrm{~atm}^{-1 / 2}$ by using a Co $\mathrm{K}_{\alpha}(\lambda=1.78897 \AA)$ radiation and $\mathbf{b ~ C u}$ $\mathrm{K}_{\alpha}(\lambda=1.54056 \AA)$ radiation. The positions of the various reflections occurring to the JCPDS data file have been indicated in the bottom part of the figures

12 and $48 \mathrm{~h}$ are shown in Figs. 2 and 3, respectively. The nitrided zone and the unnitrided core can be distinguished in the optical micrographs recorded from the specimen nitrided for $12 \mathrm{~h}$, by the distinct visibility of the grain boundaries in the nitrided zone (Fig. 2; the specimen 
Fig. 2 Light optical micrographs of the etched cross section of a Fe-4wt.\%V specimen nitrided at $580{ }^{\circ} \mathrm{C}$ for $12 \mathrm{~h}$ at a nitriding potential of $0.54 \mathrm{~atm}^{-1 / 2}$. The nitrided zone has a thickness of about $420 \mu \mathrm{m}$. Three micrographs a-c are from three different locations of the cross section of the same specimen. At the surface, the compound layer appears "white". Specimen surface, nitrided zone and unnitrided core are shown in (a). Formation of "white" phase along the grain boundaries and pronouncedly non-uniform thickness of white layer are observed in (b, c). Enlargement of region indicated by dashed rectangle in (b) is shown in (d)
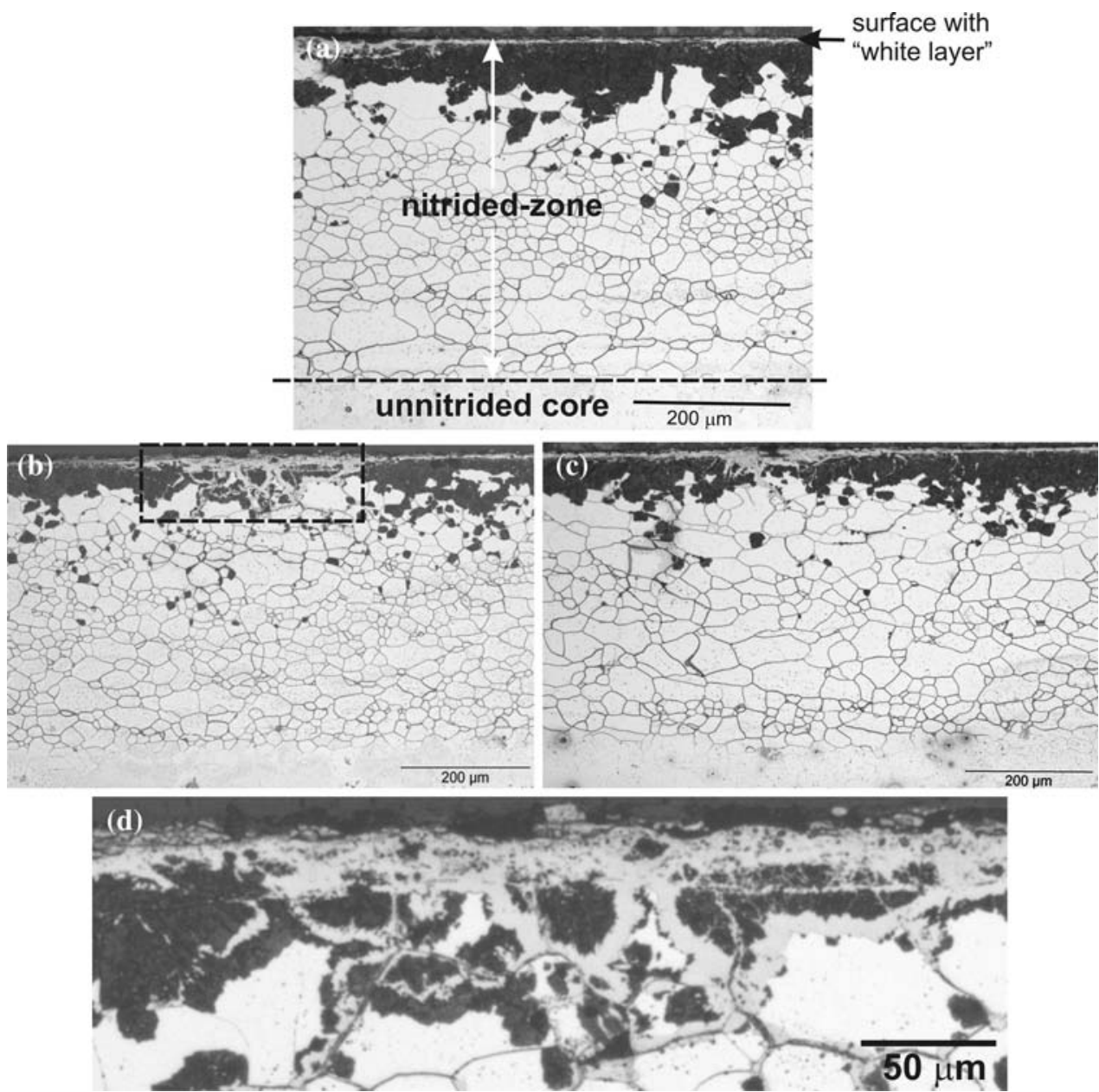

nitrided for $48 \mathrm{~h}$ was through nitrided). ${ }^{2}$ The nitrided zones of the specimens nitrided for 12 and $48 \mathrm{~h}$ show the same microstructure. The nitrided zone is composed of three regions:

1. Adjacent to the surface the "white" layer can be observed. This white layer is dominantly composed of $\gamma^{\prime}-\mathrm{Fe}_{4} \mathrm{~N}$ (or $(\mathrm{Fe}, \mathrm{V})_{4} \mathrm{~N}$; see later) phase (as indicated by the strong $\gamma^{\prime}$ reflections in the X-ray diffractograms; cf. Fig. 1). The thickness of the white layer is not uniform

\footnotetext{
${ }^{2}$ One possible explanation for the visibility of the grain boundaries in the nitrided zone, and not or less clear, in the not nitrided core, is the following. Nitride forming elements as $\mathrm{V}$ form also oxides. In the nitrided zone, $\mathrm{V}$ is bonded as nitride. The kinetics for transformation of nitrides to oxides is slow under the given conditions, which inhibits the formation of a protective oxide layer on the surface of the cross section of the nitrided zone, whereas on the surface of the nonnitrided part vanadium oxides can develop. During the etching attack, the oxide layer on the non-nitrided core of the sample acts as a protective layer. As a consequence, the contrast of the grain boundaries in the non-nitrided core of the sample is much weaker than in the nitrided part of the sample. Another possible explanation for enhanced visibility of the ferrite grain boundaries in the nitrided zone is the precipitation of excess nitrogen as nitrogen gas at the grain boundaries in the nitrided zone (see also at the end of this article).
}

along the width: at some places it has penetrated deeply into the diffusion zone, especially along the grain boundaries of the matrix (see Figs. $2 \mathrm{~d}$ and $3 \mathrm{~d}$ ). This "penetration" could have occurred along "open" grain boundaries as formed at some places (see section "Quantitative phase analysis of the surface layer (compound/"white" layer)" for the mechanism of formation of the compound layer). Other possibly suggested explanations, as relatively fast grain-boundary diffusion of nitrogen (but no such deep penetration upon nitriding pure iron) and segregation of vanadium at grain boundaries (not observed in this study; cf. Fig. 5), appear less likely.

2. Dark regions below the white layer. These regions in the diffusion zone have experienced the "discontinuous" coarsening ${ }^{3}$ leading to a microstructure composed of $\mathrm{VN} / \alpha$-Fe lamellae (for details, see Ref. [9]).

\footnotetext{
${ }^{3}$ The discontinuous coarsening reaction consists of the replacement of coherent or partly coherent, submicroscopical precipitates by a coarser lamellae-like precipitation morphology, under simultaneous relaxation of the (misfit) strain and loss of the capacity for excess nitrogen uptake [9].
} 
Fig. 3 Light optical

micrographs of the etched cross section of a Fe-4wt.\%V specimen nitrided at $580{ }^{\circ} \mathrm{C}$ for $48 \mathrm{~h}$ at a nitriding potential of $0.54 \mathrm{~atm}^{-1 / 2}$. The specimen has been through nitrided. Three micrographs a-c are from three different locations of the cross section of the same specimen. At the surface, the compound layer appears "white". An entire cross section is shown in (a). Formation of unusually pronouncedly non-uniform thickness of white layer is observed in $(\mathbf{b}, \mathbf{c})$. Enlargement of region indicated by dashed rectangle in (b) is shown in (d)


3. Bright regions at larger depth in the diffusion zone, which have experienced (only) the "continuous" precipitation of very fine (submicroscopical) vanadium-nitride particles (see also Refs. [6, 9]).

Consider again Fig. 1. For iron-based materials, the penetration/information depth is much less for $\mathrm{Cu} \mathrm{K}_{\alpha}$ than for $\mathrm{Co} \mathrm{K}_{\alpha}$ radiation (for discussion and quantification of the penetrative power of the X-rays, see Ref. [18]). The presence of VN reflections in the diffractogram recorded with Co $\mathrm{K}_{\alpha}$ radiation with, with respect to the intensity of the $\gamma^{\prime}-\mathrm{Fe}_{4} \mathrm{~N}$ reflections, more or less the same intensity as in the diffractogram recorded with $\mathrm{Cu} \mathrm{K}_{\alpha}$ radiation, whereas the $\alpha$-Fe reflections are relatively much weaker if $\mathrm{Cu} \mathrm{K}_{\alpha}$ radiation is used, already hints at the presence of $\mathrm{VN}$ precipitates in the white layer.
Quantitative phase analysis of the surface layer (compound/"white" layer)

The elemental concentration-depth profiles (EPMA results) of the nitrided layer of the $\mathrm{Fe}-4 \mathrm{wt} . \% \mathrm{~V}$ specimen, nitrided at $580{ }^{\circ} \mathrm{C}$ for $48 \mathrm{~h}$ at $0.540 \mathrm{~atm}^{-1 / 2}$, are shown in Fig. 4a together with the optical micrograph (see Fig. 4b) of the analyzed part of the cross section of the sample (which was etched after EPMA analysis; compound-layer thickness at the location of measurement is about $200 \mu \mathrm{m}$ ). In the optical micrograph, the line, along which the EPMA measurements were performed, has been indicated with a black dotted line. The compound layer characterized by a high level of nitrogen uptake (at the location chosen the compound layer was particularly thick) can be clearly distinguished from the diffusion zone underneath. 


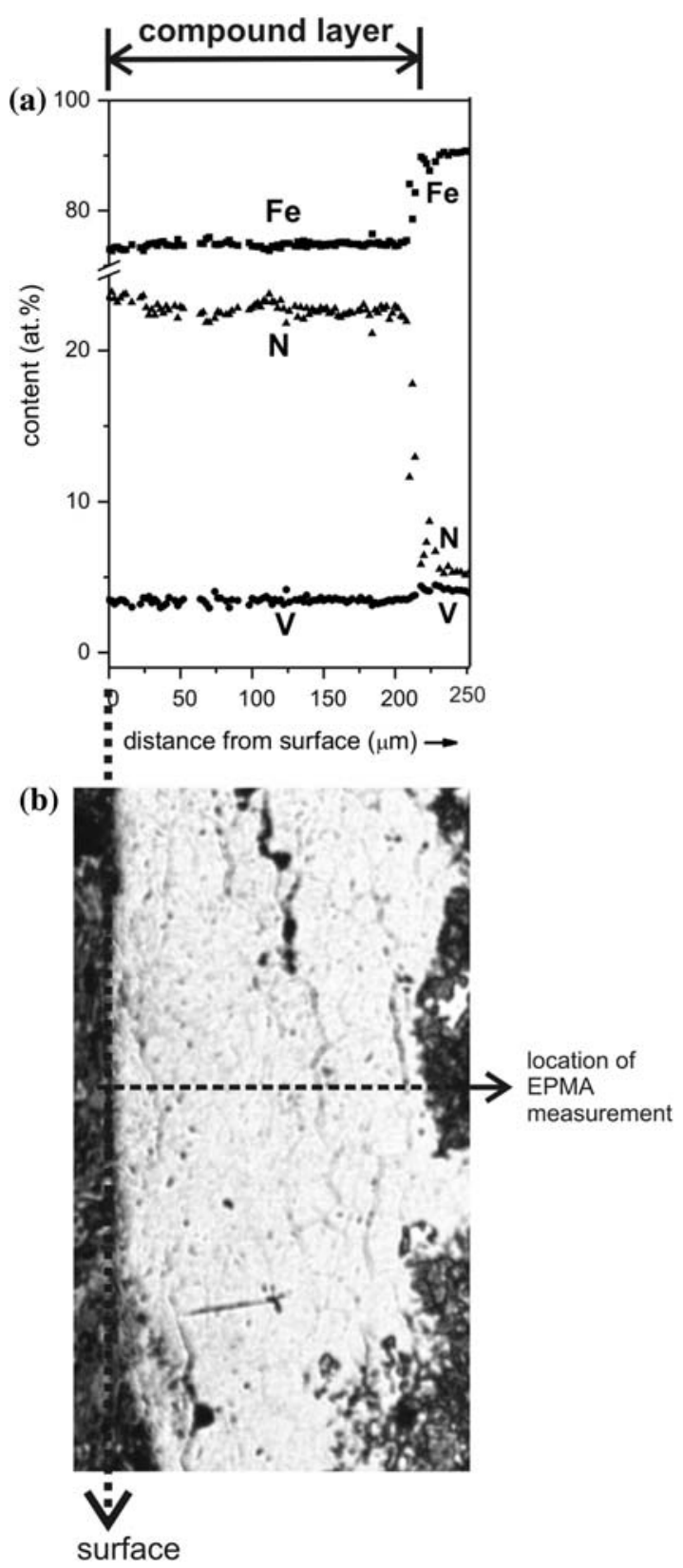

Fig. 4 a Elemental $(\mathrm{N}, \mathrm{V}, \mathrm{Fe})$ concentration-depth profiles of a $\mathrm{Fe}-4 \mathrm{wt} . \% \mathrm{~V}$ specimen nitrided at $580{ }^{\circ} \mathrm{C}$ for $48 \mathrm{~h}$ at a nitriding potential of $0.54 \mathrm{~atm}^{-1 / 2}$. b The light optical micrograph of the cross section analyzed (which was etched after EPMA analysis; same scale as abscissa in a) indicating the location of the EPMA measurements

The N, V and Fe concentrations within the compound layer, as measured with EPMA, are shown in Table 2. If it is assumed that vanadium in $\mathrm{Fe}-4 \mathrm{wt} . \% \mathrm{~V}$ alloy would not form any nitrides within the compound layer and would be present as a dissolved component in the $\gamma^{\prime}$ phase, then the nitrogen content (under the given nitriding conditions: $580{ }^{\circ} \mathrm{C}$ and $0.540 \mathrm{~atm}^{-1 / 2}$ nitriding potential) should be around 19.85 at.\% [15]. However, the observed average nitrogen content within the compound layer is about 23.1 (maximum deviation \pm 0.7 ) at.\% (see Figs. 4 and 5). If we assume that all vanadium in the compound layer is present as $\mathrm{VN}$, then the total nitrogen uptake (i.e. 23.1 at.\%) minus the vanadium content of the layer (i.e. 3.4 (maximum deviation \pm 0.4 ) at.\%) gives the amount of nitrogen (i.e. 23.1 $3.4=19.7$ at. \%) associated with $\mathrm{Fe}$ (73.5 (maximum deviation \pm 1.1$)$ at. $\%$ ) as $\gamma^{\prime}-\mathrm{Fe}_{4} \mathrm{~N}_{1-x}$ phase (X-ray diffractograms show the presence of $\gamma^{\prime}$ phase: see Fig. 1). Taking the above-mentioned given experimental values for the $\mathrm{N}$ and $\mathrm{Fe}$ contents ascribed to the $\gamma^{\prime}$ phase (19.7 and 73.5 at.\%), the nitrogen content in the $\gamma^{\prime}$ phase equals $\left(\frac{19.7 \times 100}{73.5+19.7}=\right) 21.1$ at. $\%$, which indeed is close to (but somewhat larger, see later) the composition expected for $\mathrm{Fe}_{4} \mathrm{~N}_{1-x}$ under the given nitriding conditions (i.e. (see earlier) 19.85 at. $\% \mathrm{~N}$ corresponding to $\mathrm{Fe}_{4} \mathrm{~N}_{1-x}$ with $x=0.04)$. Hence, the quantitative phase analysis indicates the presence of vanadium nitride as a separate phase within the compound layer.

At this place it is appropriate to remark that it has been suggested that $\mathrm{CrN}$ precipitates in nitrided $\mathrm{Fe}-\mathrm{Cr}$ would in reality be $(\mathrm{Cr}, \mathrm{Fe}) \mathrm{N}$ precipitates [19]. It may then also be suggested that in the present case of nitrided $\mathrm{Fe}-\mathrm{V}$ the $\mathrm{VN}$ precipitates might be $(\mathrm{Fe}, \mathrm{V}) \mathrm{N}$ precipitates. However, dedicated nitriding and denitriding experiments (reported in Refs. $[10,20])$ have demonstrated that the precipitates, as remaining after denitriding, have the stoichiometric composition, i.e. $\mathrm{CrN}$ and $\mathrm{VN}$, respectively. If the excess nitrogen uptake, upon nitriding iron-based $\mathrm{Fe}-\mathrm{Cr}$ and $\mathrm{Fe}-$ $\mathrm{V}$ alloys without compound-layer formation, would be due to the development of $(\mathrm{Cr}, \mathrm{Fe}) \mathrm{N}$ or $(\mathrm{V}, \mathrm{Fe}) \mathrm{N}$ precipitates, rather than $\mathrm{CrN}$ and $\mathrm{VN}$ precipitates, the denitriding experiments would have shown a higher nitrogen content (in at.\%) than the chromium content (in at.\%) or the vanadium content (in at.\%), which clearly is not the case $[10,20]$.

\section{Mechanism of compound layer formation}

Upon gaseous nitriding, nitrogen diffuses into and through the ferrite matrix containing dissolved vanadium, which leads to the formation of $\mathrm{VN}$ precipitates. As soon as the amount of nitrogen dissolved (at octahedral interstitial sites of the ferrite matrix) exceeds the solubility limit, $\gamma^{\prime}$ ironnitride can develop. The highest amount of nitrogen in the ferrite matrix occurs at the surface and there the ironnitride compound layer then develops. Evidently, "open" 
Table $2 \mathrm{~N}, \mathrm{~V}$ and Fe concentrations in the compound layer as determined by EPMA (within the "white" phase: see Figs. 4 and 5; average values with indication of maximal deviation) for a Fe-4wt. $\% \mathrm{~V}$ specimen nitrided at $580{ }^{\circ} \mathrm{C}$ for 12 and $48 \mathrm{~h}$ at $0.540 \mathrm{~atm}^{-1 / 2}$

$$
\text { Element content in the compound layer (from EPMA) }
$$

$\mathrm{N}$ in $\gamma^{\prime}$ phase (at.\%)

\begin{tabular}{llll}
\hline$(1)$ & $(2)$ & $(3)$ & $(4)=(1)-(2)$ \\
{$[\mathrm{N}]_{\text {total }}($ at.\%) } & {$[\mathrm{V}]($ at.\%) } & {$[\mathrm{Fe}]($ at.\%) } & $\mathrm{N}$ associated with Fe \\
& & (assuming that all V \\
& & is present as VN) (at.\%)
\end{tabular}

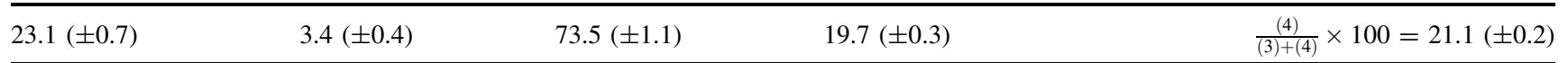

Fig. 5 The formation of $\gamma^{\prime}$ phase at grain boundaries in the nitrided region of a $\mathrm{Fe}-4 \mathrm{wt} . \% \mathrm{~V}$ specimen nitrided at $580^{\circ} \mathrm{C}$ for $12 \mathrm{~h}$ at a nitriding potential of $0.540 \mathrm{~atm}^{-1 / 2}$. a SEM image of the cross section of the specimen. b SEM image of the region indicated by the rectangle in (a). The dark contrast along the grain boundary is due to pores. c Elemental $(\mathrm{N}, \mathrm{V}, \mathrm{Fe})$ concentration-depth profiles (EPMA result) across the grain boundary at the location shown in (b); the diameter of the area, illuminated by the electron beam, is about $1 \mu \mathrm{m}$. d SEM image of another grain boundary showing $\gamma^{\prime}$ phase development along the grain boundary. The dark contrast is due to pores along the grain boundary. e Elemental (N, V, $\mathrm{Fe}$ ) concentration-depth profiles (EPMA result) across the grain boundary at the location shown in (d); the diameter of the area, illuminated by the electron beam, is about $1 \mu \mathrm{m}$. In contrast with (b), the EPMA scan has now been made at a location of minimal porosity, allowing measurement along the entire scan

(a) SEM image

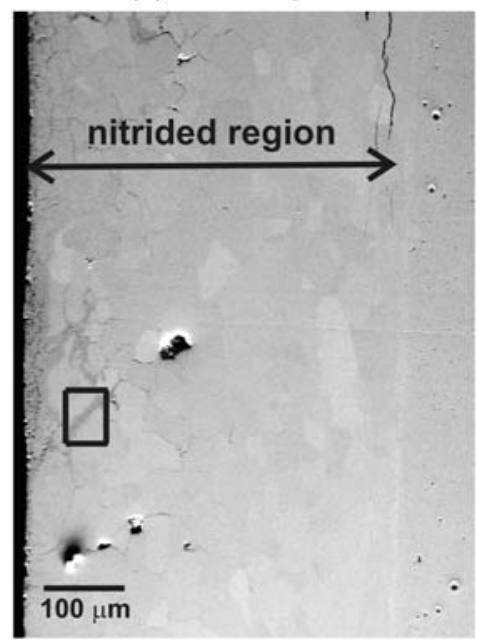

(b) SEM image

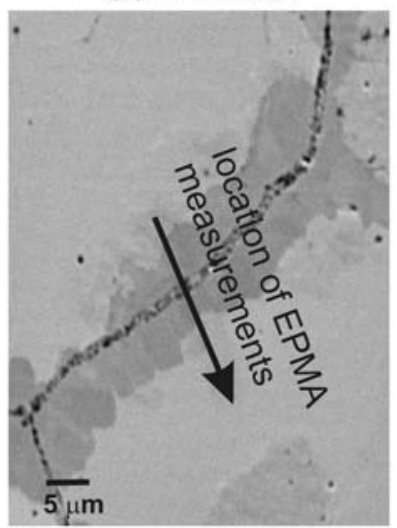

(d) SEM image

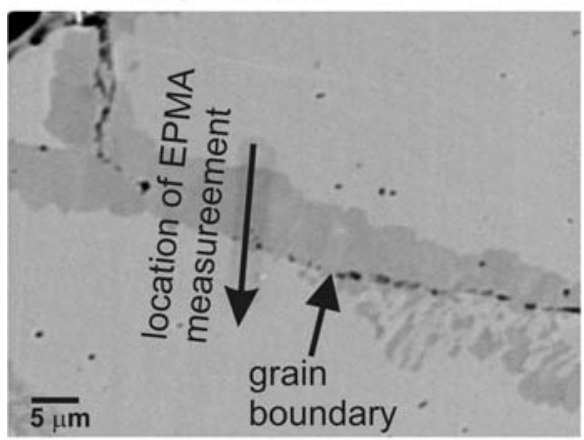

(c) EPMA result

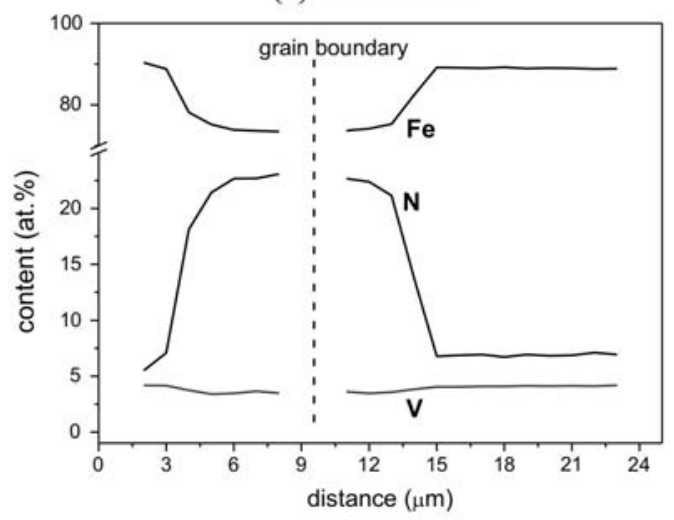

(e) EPMA result

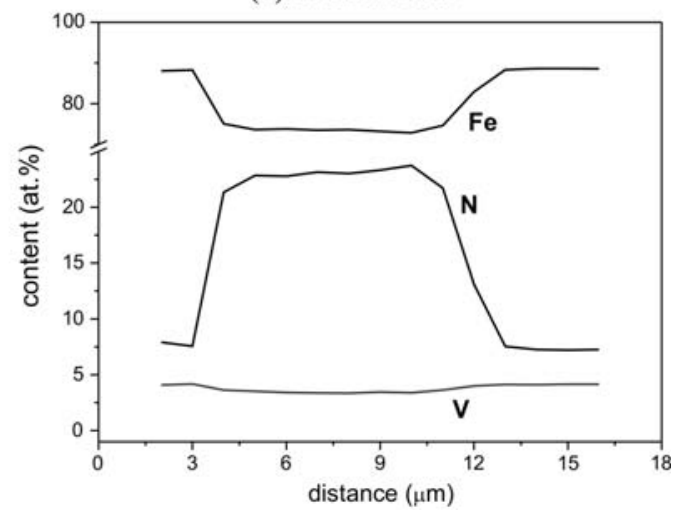




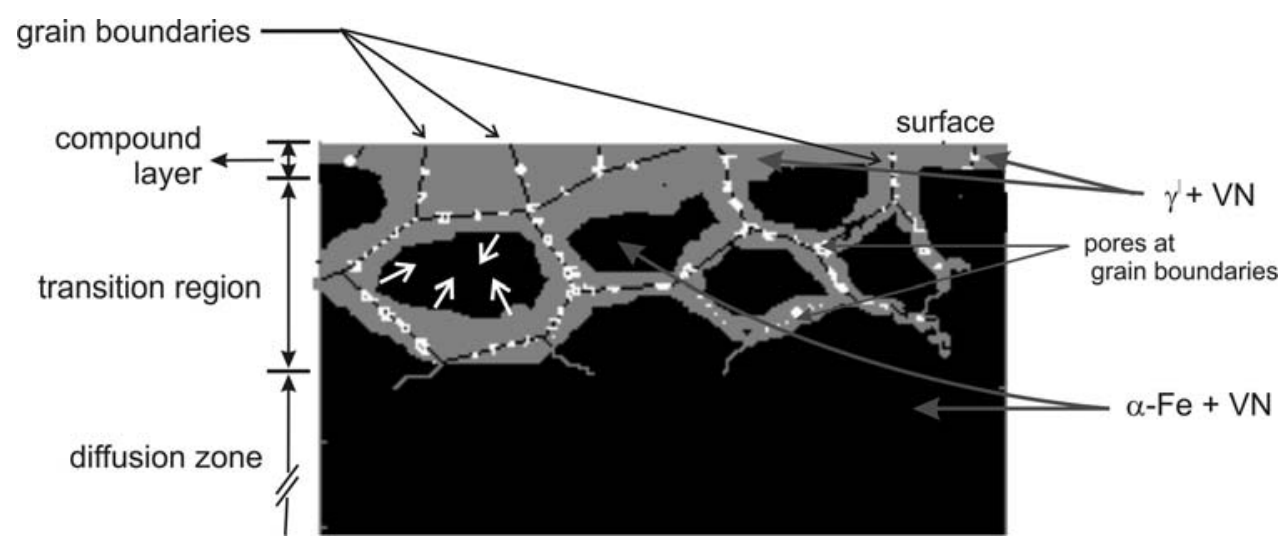

Fig. 6 Schematic diagram illustrating the mechanism for formation of the compound layer upon nitriding $\mathrm{Fe}-4 \mathrm{wt} . \% \mathrm{~V}$ alloy. In the diagram, the compound layer (composed of $\mathrm{Fe}_{4} \mathrm{~N}$ and VN phases) is shown in grey; the diffusion zone is black; the grain boundaries within the compound layer/iron-nitride phase have been indicated by black lines; the pores along the grain boundaries are shown as white dots. The directions of compound layer growth have been indicated with white arrows grain boundaries ${ }^{4}$ in direct contact with the outer gas atmosphere also provide sites for iron-nitride development. Further, "closed" grain boundaries directly connected with the surface may provide a path for relatively fast nitrogen diffusion and thus an enhanced (as compared to the adjacent bulk material) nitrogen concentration can occur as well along these grain boundaries (however, it is noted that no proof exists for a faster grain-boundary diffusion, as compared to bulk diffusion, for an interstitial as $\mathrm{N}$ in $\alpha$-Fe) and iron-nitride could develop along these "closed" grain boundaries too. On this basis, the irregular "penetration" of the substrate by the compound layer (cf. Figs. $2 d$ and $3 d$ and see Fig. 5) can be understood. After the iron-nitride phase has developed at grain boundaries, iron-nitride growth can progress toward the center of the grains more or less enclosed by iron-nitride bands along their boundaries. When a grain has fully transformed to iron-nitride (containing vanadium-nitride phase), it has become an integral part of the compound layer (see Fig. 6).

Before a grain transforms to iron-nitride and becomes part of the compound layer, VN has already precipitated in the ferrite matrix. This VN precipitation process is associated with the development of pronounced misfit strain in the ferrite matrix which leads to enhanced nitrogen solubility of the ferrite matrix, i.e. excess nitrogen uptake [23].

\footnotetext{
4 The development of "open" grain boundaries is ascribed to the coarsening (discontinuous coarsening) of the originally very fine, submicroscopical nitride precipitates (see section "Phase identification and morphology of the nitrided zone"). This coarsening of the initial (coherent) nitride particles leads to relaxation of the precipitate misfit-strain fields; thereby, the ability to accommodate excess nitrogen is reduced (or lost) leading to accumulation of "pores" at grain boundaries by the "precipitation" of $\mathrm{N}_{2}$ gas [21] (see later). The "opening" of these grain boundaries is further supported by the development of a tensile stress parallel to the surface in the top part of the diffusion zone, as shown in Ref. [22].
}

During the phase transformation of (strained) ferrite (surrounding the precipitates) to the $\gamma^{\prime}$ phase, relaxation of the internal misfit strain fields in the ferrite matrix occurs, and thereby the capacity for excess nitrogen in dissolved fashion is lost. Some excess nitrogen may then segregate at grain boundaries and form $\mathrm{N}_{2}$ gas, which leads to the development of pores at the grain boundaries (see Fig. 5b, d). As a result, the presence of some excess of nitrogen in the compound layer (a result deduced in section "Quantitative phase analysis of the surface layer (compound/ "white" layer)"), developing by the transformation of ferrite grains as described earlier, may be understood.

\section{Conclusions}

1. Upon nitriding $\mathrm{Fe}-4 \mathrm{wt} . \% \mathrm{~V}$ specimens at $580{ }^{\circ} \mathrm{C}$ and at the nitriding potential of $0.54 \mathrm{~atm}^{1 / 2}$ a "white" layer (compound layer), dominantly composed of $\gamma^{\prime}$ ironnitride, forms adjacent to the surface. The thickness of the compound layer is not uniform: at some places it penetrates deeply and irregularly into the diffusion zone, especially along the grain boundaries of the matrix.

2. The compound layer is composed of iron nitride and vanadium nitride. Vanadium is not taken up significantly in the iron nitride.

3. Iron-nitride bands formed along the grain boundaries of the matrix grow (thicken) toward the center of the ferrite grains. When a grain has fully transformed to iron nitride (containing vanadium-nitride phase), it has become an integral part of the compound layer.

Acknowledgements The authors are grateful to Mr. P. Kress for assistance with the nitriding experiments and especially to Mrs. S. Haug for carrying out the electron probe microanalysis measurements. 
Open Access This article is distributed under the terms of the Creative Commons Attribution Noncommercial License which permits any noncommercial use, distribution, and reproduction in any medium, provided the original author(s) and source are credited.

\section{References}

1. Philipps VA, Seybolt AU (1968) Trans Metall Soc AIME 242:2415

2. Pope M, Grieveson P, Jack KH (1973) Scand J Metall 2:29

3. Welch WD, Carpenter SH (1973) Acta Metall 21:1169

4. Krawitz A (1977) Scr Metall 11:117

5. Yang MM, Krawitz AD (1984) Metall Trans A 15:1545

6. Bor TC, Kempen ATW, Tichelaar FD, Mittemeijer EJ, van der Giessen E (2002) Philos Mag A 82:971

7. Djeghlal ME, Barrallier L (2003) Ann Chimie Sci Materiaux 28:43

8. Gouné M, Belmonte T, Redjaimia A, Weisbecker P, Fiorani JM, Michel H (2003) Mater Sci Eng A 351:23

9. Hosmani SS, Schacherl RE, Mittemeijer EJ (2005) Acta Mater 53:2069
10. Hosmani SS, Schacherl RE, Mittemeijer EJ (2006) Acta Mater $54: 2783$

11. Bell T (1975) Heat Treat Met 2:39

12. Bell T (1977) Source book on nitriding. American Society for Metals, Metals Park, OH

13. ASM Handbook (1991) Heat treating, vol 4. ASM International Metals Park, $\mathrm{OH}$

14. Mittemeijer EJ, Slycke JT (1996) Surf Eng 12:152

15. Mittemeijer EJ, Somers MAJ (1997) Surf Eng 13:483

16. Schacherl RE, Graat PCJ, Mittemeijer EJ (2004) Metall Mater Trans A 35:3387

17. JCPDS-International Center for Diffraction Data, PCPDFWIN, Version 2.3 (2002)

18. Delhez R, de Keijser ThH, Mittemeijer EJ (1987) Surf Eng 3:331

19. Ginter C, Torchane L, Dulcy J, Gantois M, Malchère A, Esnouf C, Turpin T (2006) La Metall Ital 7-8:29

20. Hosmani SS, Schacherl RE, Mittemeijer EJ (2008) J Mater Sci 43:2618. doi:10.1007/s10853-008-2473-9

21. Schacherl RE, Graat PCJ, Mittemeijer EJ (2002) Z Metallkd 93:468

22. Vives Díaz NE, Schacherl RE, Zagonel LF, Mittemeijer EJ (2008) Acta Mater. doi:10.1016/j.actamat.2007.11.012

23. Somers MAJ, Lankreijer RM, Mittemeijer EJ (1989) Philos Mag A $59: 353$ 